\title{
The proportion of variation in perioperative transfusion decisions in Canada attributable to the hospital
}

\author{
[La proportion de variation dans les pratiques transfusionnelles périopératoires au
} Canada imputable aux hôpitaux]

Nadine Shehata MD MSc, ${ }^{\star} † \ddagger$ Kumanan Wilson MD MSc, $\ddagger \subseteq$ C. David Mazer MD, $\|$ George Tomlinson PhD, David Streiner PhD, $\coprod^{* *}$ Paul Hébert MD MHSc (Epidemiology), †† Gary Naglie MD $\ddagger \S \ddagger \ddagger$

Purpose: Hospital variation in transfusion practices has been described previously but the proportion of variation attributable to the hospital has not. The objective of this report was to quantify hospital variation in red cell transfusion decisions perioperatively for patients undergoing coronary artery bypass surgery (CABG).

Methods: We used a cross-sectional study design using pretested self-administered mailed questionnaires sent to all anesthesiologists and cardiac surgeons involved in CABG in Canada.

Results: Responses were received from anesthesiologists from all 32 hospital sites and from cardiac surgeons from 30/32 sites $(94 \%)$. There was variation attributable to the hospital in transfusion triggers selected $(P<0.000 \mathrm{I})$. For patients who had uncomplicated $C A B G$ surgery, the range of transfusion triggers among hospitals for the intraoperative and postoperative case scenarios were $6 \mathrm{I}$ to $80 \mathrm{~g} \cdot \mathrm{L}^{-1}$ and 64 to $80 \mathrm{~g} \cdot \mathrm{L}^{-1}$, respectively. The hospital accounted for $20 \%$ of the variation in the transfusion practice intraoperatively and postoperatively. The remainder of the variation was attributable to the individual physician. Academic affiliation and the number of surgical cases performed at the hospital were not significant factors impacting on the transfusion triggers selected

Conclusion: This is the first study to quantify the variation in red cell transfusion practices according to individual physicians and the hospital. The variation attributed to the hospital is significant. The explanation for the variation in transfusion decisions that relate to the hospital needs to be explored further in order to help optimize transfusion practice.

CAN J ANESTH 2007 / 54: 11 / pp 902-907

Objectif : La variation entre les hôpitaux en ce qui touche aux pratiques transfusionnelles a été précédemment décrite, mais la proportion de cette variation imputable aux hôpitaux ne l'a pas encore été. L'objectif de ce compte-rendu était de quantifier la variation entre les hôpitaux dans les pratiques transfusionnelles périopératoires de globules rouges chez les patients subissant un pontage aortocoronarien (PAC).

Méthode : Nous avons utilisé un concept d'étude transversale en nous basant sur des questionnaires pré-testés et auto-administrés envoyés à tous les anesthésiologistes et les chirurgiens cardiaques pratiquant des PAC au Canada.

Résultats : Des réponses ont été reçues d'anesthésiologistes des 32 centres hospitaliers et de chirurgiens cardiaques de 30/32 sites (94\%). Une variation imputable à l'hôpital a été observée dans les seuils d'amorce de transfusion choisis $(P<0,0001)$. Chez les patients ayant une chirurgie PAC sans complication, la gamme de

From the Division of Hematology, ${ }^{*}$ St. Michael's Hospital, University of Toronto, Toronto; the Canadian Blood Services, $†$ the Departments of Medicine and Health Policy, Management and Evaluation, $\ddagger$ University of Toronto, Toronto; the Division of General Internal Medicine, $\mathbb{S}$ University Health Network; Toronto; the Department of Anesthesia, $\|$ St. Michael's Hospital and University of Toronto, Toronto; the Baycrest Centre for Geriatric Care, I the Departments of Psychiatry and Health Policy Management and Evaluation, ${ }^{* *}$ University of Toronto, Toronto; the Ottawa Health Research Institute Clinical Epidemiology Programme, $† \dagger$ Ottawa; and the Geriatrics Program, $\ddagger \ddagger$ Toronto Rehabilitation Institute, Toronto, Ontario, Canada.

Address correspondence to: Dr. Nadine Shehata, St. Michael's Hospital, 30 Bond Street, Queen Wing, 2-065c, Toronto, Ontario M5B

1W8, Canada. Phone: 416-864-5128; Fax: 416-864-5127; E-mail: shehatan@smh.toronto.on.ca

Conflicts of interest: None declared.

Funding: This study was supported by grant XT00045 from the Canadian Blood Services' Research and Development Program, Canada.

Canadian Blood Services as a funding agency did not have any role in the design and conduct of the study; collection, management, analysis, and interpretation of the data; and preparation, review, or approval of the manuscript.

Dr. Hébert holds the University of Ottawa Research Chair in Transfusion and Critical Care Medicine. Dr. Naglie is partially supported

by the Mary Trimmer Chair in Geriatric Medicine Research, University of Toronto.

Accepted for publication June 18, 2007.

Revision accepted August 17, 2007.

CAN J ANESTH 54: 11 www.cja-jca.org November, 2007 
seuils transfusionnels entre les hôpitaux pour les scénarios de cas peropératoire et postopératoire allait de 61 à $80 \mathrm{~g} \cdot \mathrm{L}^{-1}$ et de 64 à $80 \mathrm{~g} \cdot \mathrm{L}^{-1}$, respectivement. L'hôpital était responsable de $20 \%$ de la variation dans la pratique transfusionnelle peropératoire et postopératoire. Le reste de la variation était imputable au médecin lui-même. L'affiliation universitaire et le nombre de cas chirurgicaux effectués à l'hôpital n'ont pas constitué de facteurs significatifs ayant un impact sur les seuils de transfusion choisis.

Conclusion : Cette étude est la première à quantifier la variation dans les pratiques de transfusion de globules rouges selon les médecins eux-mêmes et l'hôpital. La variation attribuée à l'hôpital est significative. L'explication pour la variation dans les décisions de transfusion liées à l'hôpital doit être approfondie afin d'améliorer la pratique de la transfusion.

$\mathrm{R}$ ED cell transfusion rates for patients having coronary artery bypass surgery are high and are variable. In a recent retrospective study of seven Canadian centres, which included 11,812 cardiac surgical patients, $44 \%$ of patients were transfused one or more red cell units, and the percentage of patients transfused ranged from $28 \%$ to $60 \%{ }^{1}$

Transfusion practice patterns have not only been shown to vary by patient derived factors such as age, sex, the preoperative hemoglobin concentration and comorbid illnesses, ${ }^{2-4}$ but also by the physician's personal experience and knowledge, ${ }^{5}$ by practice guidelines, ${ }^{6}$ and by the hospital site. ${ }^{1,3,7,8}$ However, no study has characterized the proportion of the variation in transfusion practice that is attributable to the hospital site. By quantifying the proportion of variation according to the hospital site and individual physician practice, the relative importance of hospital factors in influencing transfusion decisions can be determined.

The purpose of this analysis was to quantify the variation attributable to the hospital for transfusion decisions made by physicians for patients undergoing coronary artery bypass surgery.

\section{Methods}

The questionnaire design and analysis have been described previously. ${ }^{3}$ In brief, we used a cross-sectional study design using self-administered mailed questionnaires sent to all cardiac surgeons and anesthesiologists in Canada at 32 hospital sites. The questionnaire consisted of eight case scenarios that simulated patient encounters, with closed-ended questions. Four case scenarios dealt with the intraoperative setting and four dealt with the postoperative setting in the intensive care unit. The four case scenarios were based on two ages (i.e., 55 and 75 yr) for each sex.
The cases were described as having no comorbidity other than coronary artery disease, with a heart rate of 90 beats. $\mathrm{min}^{-1}$, a blood pressure of $110 / 70 \mathrm{mmHg}$, euvolemic and having a mixed venous oxygen saturation of $70 \%$. Within each scenario, there were six variations, based on presence or absence of myocardial ischemia and three categories of the cardiac index (less than $2 \mathrm{~L} \cdot \mathrm{min}^{-1} \cdot \mathrm{m}^{-2}, 2$ to $2.5 \mathrm{~L} \cdot \mathrm{min}^{-1} \cdot \mathrm{m}^{-2}$ and greater than $2.5 \mathrm{~L} \cdot \mathrm{min}^{-1} \cdot \mathrm{m}^{-2}$ ). Physicians were asked to select the hemoglobin concentration for red cell transfusion (i.e., transfusion trigger) for each case scenario. The questionnaire was distributed in 2004. The Research Ethics Board at St. Michael's Hospital, Toronto, Ontario, Canada approved the study protocol.

To allow an assessment of whether physician factors may be associated with transfusion decisions, the questionnaire gathered information about the following physician characteristics: age, sex, academic affiliation, specialty, the hospital site, the number of bypass patients per year at the hospital where the physician practiced and the number of surgeries for each physician per year.

\section{Study participants}

All cardiac surgeons and anesthesiologists involved in coronary artery bypass surgery in Canada were eligible to participate in the survey. The eligible survey population was 399 anesthesiologists and 146 surgeons $(n$ $=545$ ) at 32 hospital sites. Although physicians of other specialties are involved in postoperative transfusion decisions in the intensive care unit, we only surveyed cardiac surgeons and anesthesiologists because they are involved in making transfusion decisions both in the intraoperative and postoperative periods.

\section{Statistical analysis}

DATA ANALYSIS

For descriptive analyses of the between-hospital variation, hospital-specific mean transfusion triggers were calculated for each case scenario. For each case scenario, a mixed-effects regression model was used to determine the effect of the hospital site and other factors on the transfusion trigger. The dependent variable in the models was the transfusion trigger selected for the case scenario. We included a number of characteristics of the hospitals and physicians in the regression model. Despite these, there was still substantial residual, unexplained variation. Because physicians are clustered within hospitals, we were able to partition the variation into within-hospital and between-hospital components. We allowed for clustering of physicians within a hospital by including a random intercept for the hospital variable. The random intercepts in the regression 


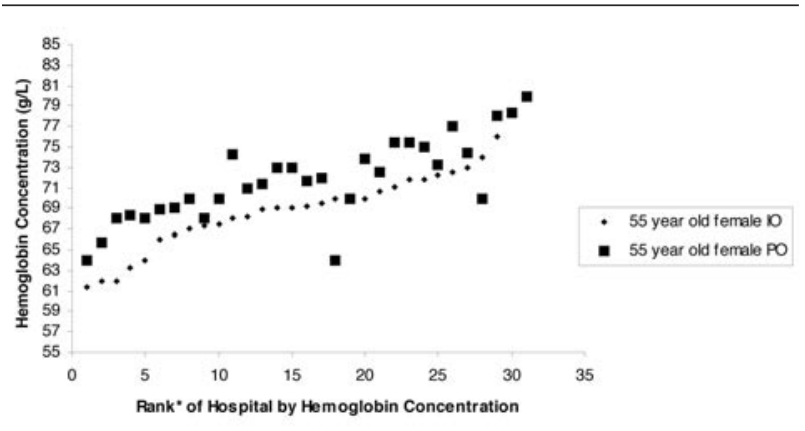

FIGURE Mean hemoglobin concentrations $\left(\mathrm{g} \cdot \mathrm{L}^{-1}\right)$ selected for red cell transfusion of a 55-yr-old female without any comorbid illness having an uncomplicated surgery, for the intraoperative $(\mathrm{IO})$ and postoperative $(\mathrm{PO})$ periods.

*The hospitals were ordered by hemoglobin concentrations selected for transfusion for the intraoperative (IO) case scenarios. The hospital with the lowest IO hemoglobin concentration is on the left $($ rank $=1)$ and the hospital with the highest mean IO hemoglobin concentration is on the right $($ rank $=31)$.

models represent the mean triggers at each hospital. By fitting a random intercept for each hospital, we allow random variation between the average values at each hospital. This induces clustering in the following way: the correlation between two responses at the same hospital is equal to the intra-cluster correlation coefficient which measures the variance between the hospitals divided by the variance between the hospitals and the variance within the hospitals. In addition, we adjusted for potential confounding by academic affiliation, the number of coronary artery bypass cases performed at each centre, the number of surgeries performed by each physician, the number of years a physician practiced, physician sex, physician age, physician specialty, and the involvement by the physician in preoperative, intraoperative and postoperative transfusion decisions. Using the results of the mixed-effects regression model we calculated the proportion of random variation that was attributable to between hospital variation by dividing the variance for the hospital random effect by the sum of the variance for the hospital random effect and the residual variance attributable to the physician.

We excluded hospitals that had less than five respondents from the regression analyses. This resulted in the exclusion of three hospitals from the analysis of the intraoperative scenarios and four hospitals from the analysis of the postoperative scenarios. These hospitals were excluded because the small number of physician responses from these hospitals may not be representative of the hospital.
The proportion of missing data for the intraoperative and postoperative case scenarios was only $1.3 \%$ $(210 / 16,368)$ and $1 \%(146 / 13,968)$, respectively, so we used complete case analysis for our analyses. ${ }^{9}$

A $P$-value less than 0.05 was considered significant for all analyses. All $P$-values were two-tailed. The statistical software package $S A S \circledR$ software system, version 8.2 (SAS Institute, Cary, NC, USA) was used for data analyses. The results were similar for the female and male case scenarios (results not shown); therefore we only present the results of the analyses for the female case scenarios.

\section{Results}

Responses were received from anesthesiologists from all 32 hospital sites and from cardiac surgeons from $30 / 32$ sites ( $94 \%)$. The response rate for the intraoperative case scenarios was $70.6 \%(345 / 489) ; 68.8 \%$ $(243 / 353)$ of all anesthesiologists responded and $75 \%(102 / 136)$ of all cardiac surgeons responded. The response rate for the postoperative case scenarios was $60.7 \%(297 / 489) ; 58 \%(205 / 353)$ of all anesthesiologists and $67.6 \%(92 / 136)$ of all cardiac surgeons responded. There were no differences between respondents and non-respondents in their sex or the province in which they practiced. There were also no significant differences in the transfusion triggers selected by anesthesiologists and cardiac surgeons. Details of respondents who were excluded have been described previously. ${ }^{3}$

Ninety percent of hospitals were academic centres. The median number of coronary artery bypass cases for physicians was 100 and the median number of cases for the hospital sites was 850 .

Looking across hospitals, the range of the mean transfusion triggers for the base case scenario of a 55yr-old female without any comorbid illness and having uncomplicated coronary artery bypass surgery was $61 \mathrm{~g} \cdot \mathrm{L}^{-1}$ to $80 \mathrm{~g} \cdot \mathrm{L}^{-1}$ intraoperatively and $64 \mathrm{~g} \cdot \mathrm{L}^{-1}$ to $80 \mathrm{~g} \cdot \mathrm{L}^{-1}$ postoperatively (Figure, Table I). Hospitals with low transfusion triggers intraoperatively also had low transfusion triggers postoperatively (Figure). The mean transfusion trigger for each hospital was not affected by the number of respondents at each site (Table I).

Univariate analyses revealed that for both the intraoperative and postoperative case scenarios the transfusion triggers differed according to the hospital where the physician practiced $(P<0.0001$ and $P=0.0003$, respectively). The Figure illustrates the mean transfusion triggers selected for the base case scenario (i.e., a 55 -yr-old female without any comorbid illnesses having uncomplicated surgery). 
TABLE I Mean hemoglobin concentrations and SD for the base case scenario: 55-yr-old female according to the hospital.

\begin{tabular}{|c|c|c|c|c|c|c|}
\hline Hospital number & $\begin{array}{l}\text { Intraoperative } \\
\text { Sample size }\end{array}$ & Mean hemoglobin $\left(g \cdot L^{-1}\right)$ & $S D\left(g \cdot L^{-1}\right)$ & $\begin{array}{l}\text { Postoperative } \\
\text { Sample size }\end{array}$ & Mean hemoglobin $\left(g \cdot L^{-1}\right)$ & $S D\left(g \cdot L^{-1}\right)$ \\
\hline 1 & 6 & 78.3 & 9.8 & 6 & 78.3 & 7.5 \\
\hline 2 & 12 & 72.5 & 9.6 & 10 & 77.0 & 9.5 \\
\hline 3 & 10 & 76.0 & 5.1 & 10 & 78.0 & 6.3 \\
\hline 4 & 7 & 67.1 & 4.9 & 5 & 70.0 & 0 \\
\hline 5 & 10 & 69.0 & 5.7 & 10 & 73.0 & 4.8 \\
\hline 6 & 10 & 68.0 & 6.3 & 7 & 74.3 & 5.3 \\
\hline 7 & 9 & 71.1 & 6.0 & 9 & 75.6 & 7.3 \\
\hline 8 & 5 & 62.0 & 8.3 & 5 & 68.0 & 4.5 \\
\hline 9 & 5 & 64.0 & 5.4 & 5 & 68.0 & 4.5 \\
\hline 10 & 13 & 69.2 & 4.9 & 12 & 71.7 & 3.9 \\
\hline 11 & 11 & 68.2 & 6.0 & 11 & 70.9 & 5.4 \\
\hline 12 & 11 & 67.3 & 7.9 & 10 & 68.0 & 4.2 \\
\hline 13 & 8 & 67.5 & 4.6 & 6 & 70.0 & 6.3 \\
\hline 14 & 11 & 71.8 & 9.8 & 9 & 75.6 & 7.3 \\
\hline 15 & 27 & 68.9 & 8.0 & 22 & 71.4 & 6.4 \\
\hline 16 & 1 & 60.0 & & 0 & & \\
\hline 17 & 1 & 70.0 & & 0 & & \\
\hline 18 & 20 & 69.5 & 6.9 & 16 & 71.9 & 6.6 \\
\hline 19 & 18 & 70.6 & 6.4 & 16 & 72.5 & 7.7 \\
\hline 20 & 9 & 72.2 & 10.9 & 6 & 73.3 & 8.2 \\
\hline 21 & 3 & 73.3 & 5.8 & 1 & 70.0 & 0 \\
\hline 22 & 8 & 70.0 & 9.2 & 5 & 64.0 & 8.9 \\
\hline 23 & 10 & 80.0 & 9.4 & 8 & 80.0 & 7.6 \\
\hline 24 & 11 & 71.8 & 7.5 & 8 & 75.0 & 5.3 \\
\hline 25 & 6 & 63.3 & 5.2 & 6 & 68.3 & 7.5 \\
\hline 26 & 11 & 66.3 & 5.0 & 10 & 69.0 & 5.7 \\
\hline 27 & 10 & 66.0 & 8.4 & 9 & 68.9 & 3.3 \\
\hline 28 & 5 & 74.0 & 5.5 & 3 & 80.0 & 10 \\
\hline 29 & 9 & 70.0 & 8.7 & 9 & 70.0 & 7.1 \\
\hline 30 & 9 & 70.0 & 7.1 & 8 & 73.8 & 5.2 \\
\hline 31 & 17 & 72.9 & 7.7 & 16 & 74.4 & 6.3 \\
\hline 32 & 7 & 61.4 & 6.9 & 5 & 64.0 & 5.5 \\
\hline 33 & 16 & 61.9 & 4.0 & 14 & 65.7 & 6.5 \\
\hline 34 & 10 & 69.0 & 5.7 & 10 & 70.0 & 4.7 \\
\hline
\end{tabular}

\section{Multivariable analysis}

Table II illustrates the proportion of random variation in transfusion triggers that is attributable to the hospital where the physician practices (i.e., between hospital variation), for the intraoperative and postoperative periods. The remainder of the random variation in hemoglobin concentration selected for transfusion is attributable to physicians within-hospitals. For example, for the case scenario of the 55-yrold female with no comorbid illnesses, the proportion of random variation in transfusion trigger attributable to the individual physician within a hospital was $82.6 \%$ and the variation attributable to the individual hospital was $17.4 \%$ (Table II). The SD of the transfusion trigger selected between physicians within a hospital was $7.3 \mathrm{~g} \cdot \mathrm{L}^{-1}$ and between hospitals was 3.4 $\mathrm{g} \cdot \mathrm{L}^{-1}$. Although smaller than the between-physician variance, the between-hospital variance in transfusion triggers was significantly different from zero for all the case scenarios illustrated $(P=0.01$ to $P=0.003)$. The largest variance attributable to the hospital site was for the case scenarios describing the elderly patient (Table II). The observed range of mean transfusion triggers selected for transfusion for the case scenarios according to the hospital site was 15 to $20 \mathrm{~g} \cdot \mathrm{L}^{-1}$. Academic affiliation and the number of surgical cases performed at the hospital were not significant factors impacting on the transfusion triggers. Similar results were noted for the postoperative case scenarios (Table II).

\section{Discussion and conclusion}

We have shown that the transfusion trigger varied significantly by hospital site for scenarios of patients having coronary artery bypass surgery. This implies that 
TABLE II Variation in transfusion triggers selected for red cell transfusion for the case scenarios based on hospital site

\begin{tabular}{|c|c|}
\hline Case scenario & $\begin{array}{l}\text { Variation attributable } \\
\text { to hospital site (\%) }\end{array}$ \\
\hline \multicolumn{2}{|l|}{ INTRAOPERATIVE } \\
\hline $\begin{array}{l}\text { 55-yr-old female with no comorbid } \\
\text { illness and CI }>2.5\end{array}$ & 17.4 \\
\hline $\begin{array}{l}55 \text {-yr-old female with no comorbid } \\
\text { illness and CI }<2\end{array}$ & 16.1 \\
\hline $\begin{array}{l}\text { 55-yr-old female with myocardial } \\
\text { ischemia and CI }>2.5\end{array}$ & 18.2 \\
\hline $\begin{array}{l}\text { 75-yr-old female with no comorbid } \\
\text { illness and CI }>2.5\end{array}$ & 23.9 \\
\hline $\begin{array}{l}75 \text {-yr-old female with no comorbid } \\
\text { illness and CI }<2\end{array}$ & 21.8 \\
\hline $\begin{array}{l}\text { 75-yr-old female with myocardial } \\
\text { ischemia and CI }>2.5\end{array}$ & 21.6 \\
\hline \multicolumn{2}{|l|}{ POSTOPERATIVE } \\
\hline $\begin{array}{l}\text { 55-yr-old female with no comorbid } \\
\text { illness and CI }>2.5\end{array}$ & 20.4 \\
\hline $\begin{array}{l}\text { 55-yr-old female with no comorbid } \\
\text { illness and CI }<2\end{array}$ & 15.5 \\
\hline $\begin{array}{l}55 \text {-yr-old female with myocardial } \\
\text { ischemia and CI }>2.5\end{array}$ & 15.2 \\
\hline $\begin{array}{l}\text { 75-yr-old female with no comorbid } \\
\text { illness and CI }>2.5\end{array}$ & 24.2 \\
\hline $\begin{array}{l}\text { 75-yr-old female with no comorbid } \\
\text { illness and } \mathrm{CI}<2\end{array}$ & 14.0 \\
\hline $\begin{array}{l}75 \text {-yr-old female with myocardial } \\
\text { ischemia and CI }>2.5\end{array}$ & 21.3 \\
\hline
\end{tabular}

$\mathrm{CI}=$ cardiac index $\left(\mathrm{L} \cdot \mathrm{min}^{-1} \cdot \mathrm{m}^{-2}\right)$.

the 'hospital' represents unmeasured characteristics of the hospital; such as hospital policy, guidelines or transfusion algorithms and patient mix seen at the hospital that affects transfusion decisions. Furthermore, it captures the average of unmeasured characteristics of physicians at the hospital (such as education received) that might vary from hospital to hospital because of, for example, proximity to medical schools. Previous cohort studies have described that there is variation in transfusion rates between hospitals, but have not determined whether there is variation for a specific patient population nor have they determined the relative contribution of this factor to the overall variation in transfusion rates. ${ }^{1,7,8,10-12}$ In addition, by using a questionnaire, we have been able to determine factors that influence physicians' decision making about when to transfuse coronary artery bypass patients. These factors may explain differences in transfusion rates that have been documented among medical centres.

We have quantified the proportion of the variation attributable to the hospital site and have shown that the hospital is an independent predictor of transfusion triggers. The proportion of variation explained by the hospital site was approximately $20 \%$, and the proportion attributable to physicians was approximately $80 \%$. To illustrate, for the case scenario of a 55 -yr-old female without comorbid illness and having uncomplicated surgery, $95 \%$ of hospitals selected transfusion triggers within $7 \mathrm{~g} \cdot \mathrm{L}^{-1}$ of the mean. The true mean triggers for hospitals span a range of about $14 \mathrm{~g} \cdot \mathrm{L}^{-1}$.

Although the proportion of the variance in the transfusion triggers that is attributable to the hospital site is relatively small in comparison to the variance attributable to individual physician characteristics $(20 \%$ vs $80 \%$ ), it is still clinically meaningful. It implies that the practice hospital is affecting transfusion decisions.

The hospital variation in red cell transfusion triggers, therefore, needs to be explored further as the rationale for this variation is unknown. In our analysis, the hospital variation is not due to whether the hospital is classified as academic or community, nor is it secondary to the number of surgical cases performed at that hospital. The hospital variation indicates a difference in practice patterns.

There are limitations to this report. The questionnaire methodology may lack validity, as responses from questionnaires may not correlate with actual behaviour. ${ }^{13,14}$ However, we attempted to develop vignettes that simulate real patients and pilot tested them to ensure that they seemed relevant to physicians. The factors that were included in the scenarios were based on a systematic literature review of variables that have been found to be associated with increased transfusion rates. ${ }^{3}$ In addition, a static patient population as presented in a survey allows for the analysis of variation in red cell transfusion decisions according to various factors whereas in cohort studies the estimation of the amount of variation is subject to confounding factors during surgery such as blood loss or comorbidities. Our study did not include information regarding the number of complex procedures performed at the individual hospitals or the severity of illness of the patients at the hospitals, which may affect the variation in transfusion practices. We did not translate the questionnaire into French, so our results may not be generalizable to physicians who are not fluent in English. Lastly, we did not find a difference in transfusion practice based on sex although several reports have documented differences in transfusion rates based on sex. ${ }^{2,4,15}$ These findings are not discordant, if men and women are transfused at the same transfusion triggers, women would be expected to receive more transfusions than men because they tend to have lower preoperative hemoglobin concentrations.

This report has demonstrated a variation in transfusion triggers for coronary artery bypass patients 
according to the hospital site. We don't know why this variance exists. However, it implies that physician practices may differ by hospital, which may relate, at least in part, to hospital transfusion policies or transfusion guidelines/algorithms, and/or to local culture. It also suggests that physician practice may change if the physician changes hospital. The best approach to address this issue is to develop evidence-based guidelines to direct transfusion practice. In areas where evidence is lacking, studies should be conducted to identify what the proper transfusion triggers should be. Developing consensus guidelines would also be an option for areas lacking evidence. We also need to explore the source of the hospital related variation so that we can better target interventions to ensure optimal transfusion practices.

\section{References}

1 Hutton B, Fergusson D, Tinmouth A, McIntyre I, Kmetic A, Hebert PQ. Transfusion rates vary significantly amongst Canadian medical centres. Can J Anesth 2005; 52: 581-90.

2 Covin R, O'Brien M, Grunwald G, et al. Factors affecting transfusion of fresh frozen plasma, platelets, and red blood cells during elective coronary artery bypass graft surgery. Arch Pathol Lab Med 2003; 127: 415-23.

3 Shehata N, Wilson K, Mazer CD, et al. Factors affecting perioperative transfusion decisions in patients with coronary artery disease undergoing coronary artery bypass surgery. Anesthesiology 2006; 105: 19-27.

4 Karkouti K, Cohen MM, McCulsky SA Sher GD. A multivariable model for predicting the need for blood transfusion in patients undergoing first-time elective coronary bypass graft surgery. Transfusion $2001 ; 41$ : 1193-203.

5 Salem-Schatz SR, Avorn, Soumerai SB. Influence of clinical knowledge, organizational context and practice style on transfusion decision making. Implications for practice change strategies. JAMA 1990; 264: 476-83.

6 Tinmouth A, Macdougall L, Fergusson D, et al. Reducing the amount of blood transfused: a systematic review of behavioral interventions to change physicians ${ }^{6}$ transfusion practices. Arch Intern Med 2005; 165 : $845-52$.

7 Surgenor DM, Churchill WH, Wallace EL, et al. The specific hospital significantly affects red cell and component transfusion practice in coronary artery bypass graft surgery: a study of five hospitals. Transfusion 1998; 38: 122-34.

8 Goodnough LT, Soegiarso RW, Birkmeyer JD, Welch HG. Economic impact of inappropriate blood transfusions in coronary artery bypass graft surgery. Am J Med 1993; 94: 509-14.
9 Harrell FE. Regression Modeling Strategies With Applications to Linear Models, Logistic Regression, and Survival Analysis. New York: Springer; 2001.

10 Goodnough LT, Johnston MF, Toy PT. The variability of transfusion practice in coronary artery bypass surgery. Transfusion Medicine Academic Award Group. JAMA 1991; 265: 86-90.

11 Stover E, Siegel LC, Parks R, et al. Variability in transfusion practice for coronary artery bypass surgery persists despite national consensus guidelines: a 24 -institution study. Institutions of the Multicenter Study of Perioperative Ischemia Research Group. Anesthesiology 1998; 88: 327-33.

12 Ozier Y, Pessione F, Samain E, Courtois F; French Study Group on Blood Transfusion in Liver Transplantation. Institutional variability in transfusion practice for liver transplantation. Anesth Analg 2003; 97: 671-9.

13 Jones TV, Gerrity MS, Earp J. Written case simulations: do they predict physicians' behavior. J Clin Epidemiol 1990; 43: 805-15.

14 Hartley RM, Charlton JR, Jarman B, Harris CM. Case history questionnaires in the study of doctors' use of resources. Are they measuring what we want? Med Care 1985; 23: 1163-70.

15 Shehata N, Naglie G, Alghamdi AA, et al. Risk factors for red cell transfusion in adults undergoing coronary artery bypass surgery: a systematic review. Vox Sang 2007; 93: 1-11. 